Dapat diakses pada: http://jkb.ub.ac.id/index.php/jkb/article/view/1790

Jurnal Kedokteran Brawijaya Vol. 29, No. 04, Agustus 2017, pp. 287-292

Online Published First: 13 Juni 2017

Artikel Penelitian

Article History: Received 1 Agustus 2016, Accepted 25 April 2017

\title{
Aktivitas Larvisida Ekstrak Terpurifikasi Rimpang Zingiber zerumbet(L) Smith terhadap Larva Aedes aegypti
}

\section{Larvicidal Activities of Zingiber zerumbet(L) Smith Rhizome Purified Extract against Aedes aegypti Larvae}

\author{
Tri Murini ${ }^{1}$, Mae SH Wahyuningsih ${ }^{1}$, TBT Satoto ${ }^{2}$, Achmad Fudholi $^{3}$ \\ ${ }^{1}$ Departemen Farmakologi dan Terapi, Fakultas Kedokteran Universitas Gadjah Mada Yogyakarta \\ ${ }^{2}$ Departemen ParasitologiFakultas Kedokteran Universitas Gadjah Mada Yogyakarta \\ ${ }^{3}$ Departemen Teknologi FarmasiFakultas Farmasi Universitas Gadjah Mada Yogyakarta
}

\begin{abstract}
ABSTRAK
Saat ini ditemukan bahwa larva nyamuk telah resisten terhadap larvisida konvensional. Oleh karena itu, penting untuk mengembangkan larvisida baru dari sumber bahan alam seperti rimpang $Z$. zerumbet, pada penelitian yang sebelumnya berpotensi sebagai larvisida pada Artemia salina Leach dan Anopheles nunestovary. Aktivitas larvisida ekstrak metanol rimpang $Z$. zerumbet yang telah dipurifikasi belum pernah diteliti. Tujuan penelitian ini adalah untuk mengkaji aktivitas larvisida ekstrak terpurifikasi rimpang Z. zerumbet terhadap larva Ae. aegypti. Penelitian ini merupakan penelitian eksplorasi laboratories dengan rancangan post test-only control group. Penelitian ini dilakukan pada dua ekstrak yaitu ekstrak metanol rimpang Z. zerumbet dan ekstrak metanol rimpang Z. zerumbet yang dipurifikasi dengan petroleum eter (PE). Dua puluh lima larva instar III-IV Ae. aegypti dipapar dengan tujuh konsentrasi yang berbeda dari ekstrak metanol rimpang Z. zerumbet. Tingkat kematian larva dihitung dan kemudian dianalisis dengan menggunakan regresi analisa probit untuk mendapatkan $\mathrm{LC}_{50}$. Setelah mengetahui $\mathrm{LC}_{50}$ tersebut, studi dilanjutkan dengan purifikasi ekstrak metanol $Z$. zerumbet menggunakan PE sebagai pelarut. Hasil ekstrak yang telah dipurifikasi baik yang larut maupun tidak larut PE diperlakukan pada larva instar III-IV Ae.aegypti menggunakan metode yang sama seperti yang disebutkan terdahulu. Nilai LC $_{50}$ ekstrak metanol, larut PE dan tidak larut PE hasil purifikasi ekstrak metanol rimpang Z. zerumbet adalah $153,57 \pm 4,01 \mathrm{ppm} ; 67,01 \pm 2,35 \mathrm{ppm}$; dan $2287 \pm 147,91 \mathrm{ppm}$. Purifikasi ekstrak metanol rimpang $Z$. zerumbet yang larut $P E$ memiliki aktivitas larvisida yang kuat terhadap larva instar III-IV Ae. aegypti dan mempunyai potensi untuk dikembangkan sebagai bahan larvisida baru.
\end{abstract}

Kata Kunci: Ekstrak metanol, larvisida, purifikasi, Z. zerumbet

\section{ABSTRACT}

Recently, it is found that mosquito larvae was resistant to conventional larvicidal. Therefore, it is important to develop a new larvicidal from natural resources such as Z. zerumbet rhizome which previously study potential for larvicidal on Artemia salina Leach and Anopheles nunestovary. Meanwhile, the study on larvicidal activity of purified methanol extract of Z. zerumbet rhizome has not been studied. The aim of this study was to investigate larvicidal activity of purified methanol extract of Z. zerumbet rhizome against Ae. aegypti larvae. It was an exploratory experimental laboratory study with posttest-only control group design. The study was conducted using two extracts, there were methanol extract and methanol extract of Z. zerumbet rhizome purified by petroleum ether (PE), respectively. Twenty five of instars III-IV larvae of Ae. aegypti were treated with seven different concentration of Z. zerumbet methanol extract. The larva mortality was calculated and the $L C_{50}$ values were determined through probit regression analysis. After knowing the $L C_{50}$ the study was continued by purifying methanol extract using petroleum ether (PE) as a solvent. The purified methanol extract was treated to Ae. aegypti larva by the same method as mentioned previously. The $L C_{50}$ of methanol extract, $P E$-soluble and

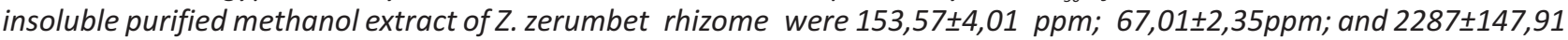
ppm respectively. The PE-soluble purified methanol extract of Z. zerumbet rhizome had highest larvacidal activity against instars III-IV larvae of Ae. aegyptiand therefore it is potential to develop as new larvacidal agent.

Keywords: Larvicidal, methanol extract, purification, Z. zerumbet

Korespondensi: Tri Murini. Departemen Farmakologi dan Terapi, Fakultas Kedokteran Universitas Gadjah Mada Yogyakarta, Gedung Radiopoetro Lantai II Sayap Timur, Jl. Farmako, Sekip Utara, Daerah Istimewa Yogyakarta 555281 Tel. (0274) 511103 Email: murini28@yahoo.co.id 


\section{PENDAHULUAN}

Iklim tropis Indonesia memungkinkan nyamuk dapat berkembang biak dengan baik. Nyamuk dapat berfungsi sebagai vektor penyebar penyakit-penyakit seperti demam berdarah dengue, filariasis, malaria, chikungunya dan encephalitis. Penanggulangan penyakit menular, yang disebabkan oleh vektor selain dengan pengobatan terhadap penderita, juga dilakukan upaya-upaya pengendalian vektor termasuk mencegah kontak dengan vektor guna mencegah penularan penyakit. Untuk menghindar vektor penyebar ini akan lebih efektif apabila vektor diberantas ketika mereka masih dalam bentuk larva. Penggunaan larvisida dapat menekan kepadatan populasi vektor serendah-rendahnya. Pemberantasan larva nyamuk dengan menggunakan larvisida yang hingga kini masih dipakai adalah temefos. Resistensi larva Aedes aegypti terhadap temefos telah dilaporkan terjadi di Indonesia daerah Surabaya (1), dan Jakarta (2), sementara di luar negeri juga terjadi Colombia (3), Brazil bagian timur (4) dan di distrik Jazan Saudi Arabia (5).

Salah satu diantara cara pengendalian vektor tersebut dengan menggunakan insektisida kimia sintetik (6). Ternyata penggunaan insektisida kimia sintetik secara terus menerus telah mengakibatkan kerusakan lingkungan dan merusak ekosistem yang ada disekitarnya. Insektisida atau larvisida yang aman terhadap lingkungan adalah pestisida yang secara selektif toksik terhadap serangga sasaran, dan mudah mengalami biodegradasi di alam sehingga dapat digunakan pada manajemen program pengendalian serangga sasaran (7). Penggunaan produk bioaktif alami dengan potensi larvisida banyak dikembangkan sebagai alternatif terhadap berkembang biaknya larva dari berbagai macam nyamuk.

Insektisida atau larvisida yang aman terhadap lingkungan adalah pestisida yang secara selektif toksik terhadap serangga sasaran, dan mudah mengalami biodegradasi di alam sehingga dapat digunakan pada manajemen program pengendalian serangga sasaran (7). Penggunaan produk bioaktif alami dengan potensi larvisida banyak dikembangkan sebagai alternatif terhadap berkembang biaknya larva dari berbagai macam nyamuk

Zingiber zerumbet (L) (J.E.Smith) di Indonesia dikenal dengan nama lempuyang gajah merupakan tanaman obat yang sering dipakai sebagai campuran jamu dalam industri obat tradisional. Kandungan kimia Z. zerumbet ditinjau dari studi fitokimia terdapat senyawa golongan terpenoid (zerumbon, zederon), alkaloid, fenol termasuk flavonoid (derivat kaempferol), komponen aromatik ( $P$ hidroksibezaldehid, vanilin) dan saponin (8-10). Penelitian sebelumnya menyatakan bahwa ekstrak diklormetan $Z$. zerumbet mempunyai aktivitas terhadap larva Artemia salina Leach nilai $\mathrm{LC}_{50}: 40,4 \mathrm{ug} / \mathrm{mL}$ dan sebagai larvisida pada Anopheles nuneztovary dengan harga $\mathrm{LC}_{50}: 62,8 \mu \mathrm{g} / \mathrm{mL}$ pada pengamatan 48 jam (11). Berdasarkan latar belakang diatas maka penelitian ini dilakukan untuk mengkaji apakah ekstrak terpurifikasi $Z$. zerumbet mempunyai efek larvisida pada larva nyamuk $A$ e. aegypti. Tujuan penelitian ini untuk mengkaji aktivitas ekstrak terpurifikasi rimpang $Z$. zerumbet pada larva nyamuk Ae. Aegypti.

\section{METODE}

\section{Desain Penelitian}

Penelitian ini termasuk jenis penelitian eksploratif eksperimental laboratorium dengan rancangan posttest only control group dan menggunakan larva instar III-IV nyamuk Ae.aegypti yang dikembangbiakkan di laboratorium Parasitologi Fakultas Kedokteran Universitas Gadjah Mada. Penelitian dilakukan terhadap dua ekstrak yaitu ekstrak metanol dan ekstrak terpurifikasi dengan petroleum eter (PE). Masing-masing ekstrak dilakukan dalam 7 kelompok dengan konsentrasi berbeda dan 2 kelompok kontrol yaitu kontrol negatif tanpa pemberian ekstrak rimpang $Z$. zerumbet dan kontrol positif yaitu larva instar III- IV Ae. Aegypti yang dipapar selama 24 jam dengan temefos $1 \mathrm{ppm}$

\section{Bahan Uji}

Bahan tanaman yang digunakan adalah rimpang $Z$. zerumbet diperoleh dari desa Jatimulyo, Kulon Progo yang diambil bulan Mei 2014. Bahan ini meliputi, metanol standar teknis, petroleum eter standart teknis, etil acetat standart teknis, silika gel $\mathrm{GF}_{254}$, larva instar III-IV nyamuk Ae. aegypti

\section{Cara Penelitian}

\section{PreparasiEkstrak Metanol}

Lima ratus gram serbuk kering rimpang $Z$. zerumbet diekstraksi dengan cara maserasi disertai pengadukan selama 24 jam pada suhu kamar menggunakan 1 liter metanol. Penyaringan dilakukan menggunakan corong buchner dan ampasnya dimaserasi kembali dengan cara yang sama sebanyak dua kali kemudian disaring. Filtrat yang didapat digabung dan diuapkan dengan menggunakan rotary evaporator, sehingga diperoleh ekstrak metanol kental (12). Keberhasilan ekstraksi dipantau dengan metode Kromatografi Lapis Tipis (KLT)

\section{Preparasi Ekstrak Terpurifikasi}

Dua puluh lima gram ekstrak metanol rimpang Z. Zerumbet kental dipurifikasi menggunakan $200 \mathrm{ml}$ petroleum eter (PE) dan disentrifus pada 5000rpm [Sentrifus (Hitachi $18 \mathrm{PR} / 5$, Automatic high speed refrigerated)] selama 15 menit, sehingga diperoleh supernatan PE yang mengandung senyawa larut $P E$ dan pelet yang mengandung senyawa tidak larut PE. Supernatan diuapkan sehingga diperoleh ektrak terpurifikasi larut PE. Keberhasilan penyarian ini dimonitor dengan metode kromatografi lapis tipis (KLT) yang ditandai dengan tidak adanya atau sesedikit mungkin kesamaan bercak antara kedua komponen bahan tersebut. Selanjutnya dua komponen bahan baik yang larut maupun tidak larut PE diuji aktivitasnya terhadap larva Ae. aegypty.

\section{Kolonisasi Larva Ae.aegypti}

Proses kolonisasi larva Ae. aegypty dilakukan di Laboratorium Parasitologi Fakultas Kedokteran Universitas Gadjah Mada menggunakan metode sesuai prosedur yang ada (13).

\section{Uji Aktivitas Larvisida}

Sebelum melakukan uji aktivitas sebagai larvisida, dilakukan uji pendahuluan terlebih dahulu agar diperoleh satu serial konsentrasi ekstrak metanol rimpang $Z$. zerumbet yang memenuhi persyaratan guna menentukan nilai $\mathrm{LC}_{50}$. Penentuan nilai $\mathrm{LC}_{50}$ menggunakan regresi analisis Probit. Penelitian ini menggunakan 7 konsentrasi ekstrak metanol rimpang $Z$. zerumbet $(125 ; 135 ; 145,80$; 157,$46 ; 170,06 ; 183,67$ dan 200ppm) dan 2 kontrol (positif dan negatif) disuspensikan dengan tween 80 beberapa tetes, kemudian diberi air hingga $100 \mathrm{ml}$, kemudian dimasukkan dalam wadah plastik yang bervolume $200 \mathrm{ml}$. Masing-masing wadah berisi 25 ekor larva instar III- IV Ae. aegypti. Perlakuan yang sama dilakukan juga pada ekstrak terpurifikasi larut PE dengan 7 konsentrasi ( 50; 55,15; 
60,66; 73,41; 80,74 dan 90ppm); 7 konsentrasi ekstrak terpurifikasi tidak larut PE (1600; 1792; 2007,04; 2247,88; 2517,63; 2819,75 dan 3200ppm) dan 2 kontrol (positif dan negatif). Perhitungan larva yang mati dilakukan 24 jam setelah pemberian ekstrak metanol dan ekstrak terpurifikasi baik yang larut maupun tidak larut dalam PE. Larva dinyatakan mati apabila tenggelam atau tidak bergerak setelah diganggu atau disentuh dengan pipet pada sifon atau daerah toraks (12). Pengujian baik ekstrak metanol maupun ekstrak terpurifikasi yang larut maupun tidak larut dalam PE diulang sebanyak tiga (3) kali.

Pembuatan Preparat Morfologi Larva Instar III- IV Ae. aegypti

Larva instar III- IV Ae. Aegypti yang mati akibat dipejankan selama 24 jam dengan ekstrak metanol dan ekstrak purifikasi larut PE dibuat preparat, dengan cara diletakkan diatas object glass dengan mengatur posisi larva. Larva ditetesi dengan gelatin dan didiamkan beberapa saat sampai mengeras kemudian ditetesi dengan perekat entelan dan ditutup dengan deck glass. Proses serupa dilakukan juga pada larva instar III-IV Ae. aegypti kontrol negatif dan kontrol positif Preparat-preparat tersebut diamati dengan menggunakan mikroskop merk Zeiss, tipe Stemi 1000 dengan perbesaran 4X, 4 lensa objektif dan 10 lensa okuler.

\section{Analisa Data}

Aktivitas larvisida digambarkan dengan nilai $\mathrm{LC}_{50}$ dan $\mathrm{LC}_{90}$ yang ditetapkan dengan regresi analisis probit menggunakan program A.Woods U.N.S.W. versi 1.1

\section{HASIL}

Gambar 1, menunjukkan profil kromatografi lapis tipis (KLT) dari kedua bercak yang diuji. Deteksi dengan sinar UV $254 \mathrm{~nm}$ pada kromatogram A terdapat bercak yang berwarna biru tua (tanda panah) merupakan senyawa yang aktif (major coumpound) terlarut dalam esktrak metanol. Sebaliknya, pada kromatogram B yang merupakan ekstrak terpurifikasi, bercak warna biru tua (gambar panah) menunjukkan bahwa zat aktif (major coumpound) terlarut dalam petroleum eter (PE). Pada kromatogram $C$ yang telah dideteksi dengan Serium sulfat, bercak berwarna coklat (tanda panah) mengindikasikan bahwa kandungan yang terdapat dalam ektrak terpurifikasi merupakan golongan terpenoid.

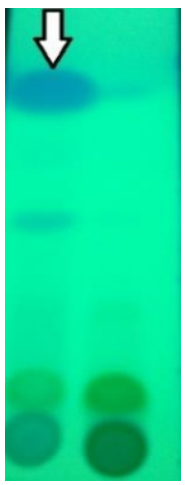

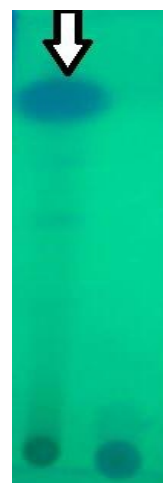

B

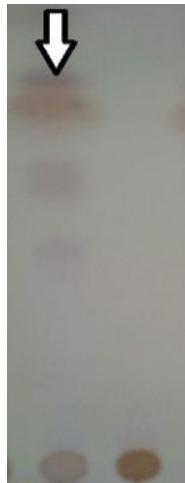

Gambar 1. Profil kromatografi lapis tipis rimpang $Z$. zerumbet
Keterangan:

A: ekstrak metanol, deteksi UV254; B: purifikasi larut dan tidak larut PE, deteksi UV254; C: purifikasi larut dan tidak larut PE, deteksi reagen

Serium sulfat; fase diam: silika gel GF254 dan fase gerak (washbenzen: etil asetat $3: 1 ; \mathrm{v} / \mathrm{v}$ )

Uji Aktivitas Larvisida Ekstrak Metanol dan Ekstrak Terpurifikasi Larut dan Tidak Larut PE Rimpang Z. zerumbet

Hasil analisis probit aktivitas larvisida dengan bahan uji ekstrak metanol, ekstrak terpurifikasi larut dan tidak larut PE dari rimpang Z. zerumbet. dengan pemajanan 24 jam terhadap larva Ae.aegypti, disajikan dalam nilai $\mathrm{LC}_{50}$ dan LC $_{90}$ pada tabel 1

Tabel 1. Nilai $L C_{50}$, dan $\mathrm{LC}_{90}$

\begin{tabular}{lrr}
\hline kelompok bahan & \multicolumn{2}{c}{ Rata-rata (ppm) \pm SD } \\
\cline { 2 - 3 } & \multicolumn{1}{c}{ LC $_{\mathbf{5 0}}$} & \multicolumn{1}{c}{$\mathbf{L C}_{\mathbf{9 0}}$} \\
\hline Ekstrak metanol & $153,57 \pm 4,01$ & $226,59 \pm 10,47$ \\
Ekstrak terpurifikasi larut PE & $67,01 \pm 2,35$ & $90,00 \pm 2,38$ \\
Ekstrak terpurifikasi tidak larut PE & $2287 \pm 147,91$ & $3947,80 \pm 186$ \\
\hline
\end{tabular}

Pengamatan morfologi larva instar III-IV Ae. aegypti secara mikroskopis setelah dipajankan selama 24 jam dengan ekstrak metanol maupun ektrak terpurifikasi larut PE rimpang Z. zerumbet disajikan pada Gambar 2 dan 3. Gambar 2 menyajikan potongan kepala (cephal) dan thorax sedangkan Gambar 3 merupakan potongan pada abdomennya.

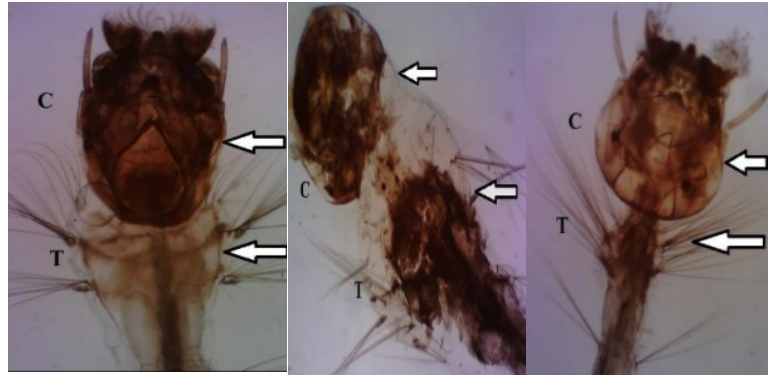

K3

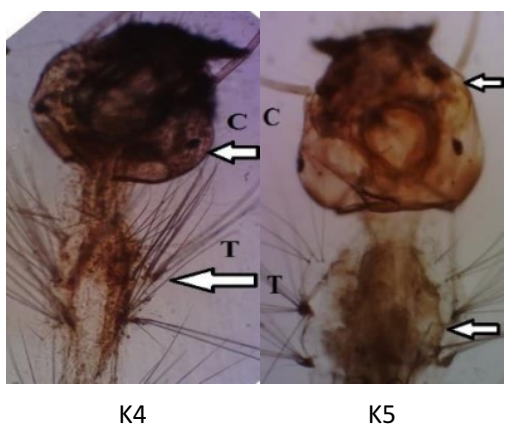

Gambar 2. Fotomikroskopi morfologi larva instar III-IV Ae. Aegypti bagian cephal dan thorak dengan pembesaran $4 \mathrm{X}$ Keterangan:

K1: kontrol negatif; K2: kontrol positif (temefos $1 \mathrm{ppm}$ ); K3: ekstrak metanol (200 ppm); K4: ekstrak terpurifikasi larut PE (90ppm); K5: ekstrak terpurifikasi tidak larut PE (3200 ppm); C: (cephal); T (thorax).

Tanda panah menunjukkan adanya kerusakan baik pada daerah cephal maupun thorax (rambut lateral posisi tidak beraturan). 


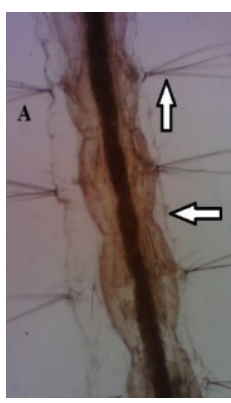

K 1

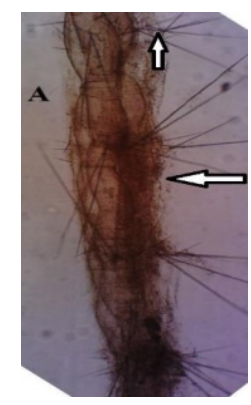

K4

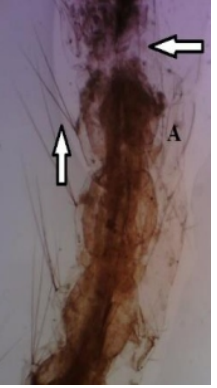

K2

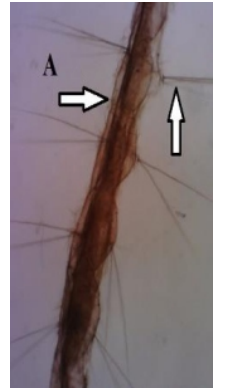

K3

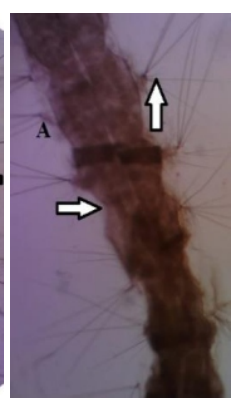

K5

Gambar 3. Fotomikroskopi morfologi larva instar III-IV Ae. aegypti bagian abdomen dengan pembesaran $4 \mathrm{X}$

\section{Keterangan:}

K1: kontrol negatif; K2: kontrol positif (temefos 1 ppm); K3: ekstrak metanol (200 ppm); K4: ekstrak terpurifikasi larut PE

(90 ppm); K5: ekstrak terpurifikasi tidak larut PE (3200 ppm); A: (abdomen).

Tanda panah menunjukkan adanya kerusakan pada daerah abdomen dengan posisi rambut lateral tidak beraturan

\section{DISKUSI}

Ekstraksi dan Hasil Purifikasi Ekstrak Metanol Rimpang Z. zerumbet

Ekstraksi rimpang Z. zerumbet dengan pelarut metanol bertujuan untuk mendapatkan senyawa aktif yang bersifat polar. Dilihat dari profil KLT (Gambar 1A) menandakan bahwa proses ekstraksinya telah sempurna karena senyawa polar dari rimpang $Z$. zerumbet telah tersari dengan sempurna.

Profil KLT pada ekstrak terpurifikasi, tampak ada perbedaan yang cukup jelas antara ekstrak purifikasi yang larut dan tidak larut petroleum eter (PE), karena terjadi pemisahan yang sempurna antara kedua senyawa tadi. Pemisahan sempurna ditandai dengan sedikitnya atau tidak adanya bercak-bercak senyawa duplikasi antara kedua profil senyawa tersebut. Kepastian tidak adanya duplikasi antara kedua senyawa ini sangat penting, karena kemungkinan antara kedua senyawa tersebut terkandung senyawa aktif yang akan membuat data perbandingan aktivitas larvisida antar kedua senyawa tersebut tidak valid.

Fase gerak yang digunakan pada KLT adalah washbenzen dan etil asetat dengan perbandingan $3: 1, \mathrm{v} / \mathrm{v}$. Washbenzen bersifat non polar sedangkan etil asetat bersifat polar. Besarnya volume perbandingan antara washbenzen dan etil asetat mengakibatkan senyawa larut PE yang bersifat polar lebih banyak tertarik ke atas dibandingkan senyawa tidak larut PE yang cenderung bersifat semipolar. Setelah dideteksi dengan sinar UV $_{254}$, pemisahan bercak antara kedua senyawa tersebut menjadi jelas, demikian juga setelah disemprot dengan reagen Serium sulfat, pemisahan bercak antara kedua senyawa tersebut menjadi jelas. Hal tersebut menunjukkan bahwa proses purifikasi telah sempurna dimana senyawa non polar dengan semipolar dari ekstrak metanol rimpang $Z$. zerumbet telah terpisah sempurna. Hasil penyemprotan dengan reagen serium sulfat mengindikasikan bahwa purifikasi yang larut $P E$ merupakan golongan terpenoid. Telah dilakukan isolasi dari fraksi kloroform diperoleh senyawa aromatik dan flovonoid (14) dan isolasi dari akar Z. zerumbet menghasilkan senyawa golongan terpenoid (15).

Uji Aktivitas Larvisida Ekstrak Metanol dan Ekstrak Terpurifikasi Larut dan Tidak Larut PE Rimpang Z. zerumbet

Ekstrak terpurifikasi dengan PE, menghasilkan supernatan yang berisi kandungan senyawa yang larut dalam PE dan pelet yang berisi senyawa tidak larut $P E$, senyawa yang terdapat pada ekstrak metanol terpisah menurut kepolarannya. Senyawa non polar cenderung larut dalam PE sementara yang polar tidak larut dalam PE. Berdasarkan hasil uji regresi analisis probit, didapatkan bahwa nilai $\mathrm{LC}_{50}$ dan $\mathrm{LC}_{90}$ pada senyawa larut $\mathrm{PE}(67,01 \pm 2,35$ ppm dan 90,00 $\pm 2,38$ ppm) lebih kecil dibandingkan dengan senyawa tidak larut PE $(2287 \pm 147,91 \mathrm{ppm}$ dan $3947,80 \pm 186 \mathrm{ppm})$ maupun ekstrak metanol $(153,57 \pm 4,01$ ppm dan 226,59 $\pm 10,47$ ppm) saja. Hal tersebut dapat diartikan bahwa senyawa larut dalam PE mempunyai aktivitas larvisida lebih besar dibandingkan dengan senyawa tidak larut PE dan ekstrak metanol. Selain itu, dapat disimpulkan bahwa senyawa aktif yang lebih poten sebagai larvisida lebih banyak terkandung dalam senyawa yang larut dalam PE. Penelitian terdahulu menunjukkan bahwa ekstrak diklormetan rimpang $Z$. Zerumbet terhadap larva Ae.aegypti mempunyai nilai $\mathrm{LC}_{50}: 89,8 \mathrm{ug} / \mathrm{ml}$ dan $\mathrm{LC}_{90}$ : $170,5 \mathrm{ug} / \mathrm{ml}$ pada pengamatan $48 \mathrm{jam}$, sedangkan dengan ekstrak metanol LC L0 $_{50}: 293,2 \mathrm{ug} / \mathrm{ml}$ danLC 90 : 471,6ug/ml (11). Sifat kepolaran pada solven berpengaruh terhadap nilai $\mathrm{LC}_{50}$ dan $\mathrm{LC}_{90}$, diklormetan maupun PE merupakan solven yang bersifat non polar akan melarutkan bahan yang bersifat non polar. Ekstraksi dari bahan tanaman dengan pelarut spesifik memberikan pengaruh yang besar dalam bioaktivitas yang dihasilkan dan memungkinan bahwa senyawa aktif dalam jumlah besar larut dengan pelarut tertentu.

\section{Morfologi Larva Instar III-IV Ae.aegypti}

Hasil pengamatan morfologi secara mikroskopis pada larva instra III-IV (Gambar 2) pada kontrol air terlihat utuh tanpa adanya kerusakan baik pada daerah cephal maupun thorax. Pada kontrol positif (K2) yang diberi temefos konsentrasi 1ppm terjadi kerusakan pada daerah cephal dan thorax, demikian juga pada K3 (ekstrak metanol pada pemberian 200ppm) dan K4 (purifikasi larut PE dengan konsentrasi $90 \mathrm{ppm}$ ) juga terjadi kerusakan pada cephal dan thorax, sedang rambut yang terdapat pada daerah thorax menjadi tidak beraturan dan thorax mengalami penyusutan dibandingkan dengan kontrol negatif (K1). Pada K5 (ektrak terpurifikasi tidak larut dalam PE konsentrasi 3200ppm) kerusakan daerah cephal maupun thorax tidak begitu parah dibandingkan dengan K2, K3 maupun K4. Kerusakan pada daerah thorax juga terjadi pada larva Ae. aegypti setelah dipajankan dengan filtrat Memnoniella echinata (16) dan ekstrak etanol biji Pachyrrhizus erosus (17). Pada Gambar 3, K2, K3 dan K4 
rusak dan posisi rambut lateral tidak beraturan, sedangkan pada K3 abdomen tersebut menyusut. Pada K5 daerah abdomen terlihat sedikit menyusut dan rambut lateralnya tidak begitu rusak posisinya dibandingkan dengan K2, K3 dan K4. Penyusutan pada daerah abdomen larva Ae. aegypti juga terjadi setelah diberi ekstrak etanol biji Pachyrrhizus erosus (17) dan ekstrak aseton daun $I$. cairica(18). Kerusakan pada daerah abdomen pada larva Ae. aegypti juga terjadi setelah dipejankan dengan ekstrak air I.Suffruticosa (19) dan ekstrak heksan daun dan batang Achyranthes aspera (20). Terjadinya kerusakan larva Ae.aegypti tersebut diatas kemungkinan senyawa aktif yang terdapat pada masing-masing tanaman akan mempengaruhi kelangsungan hidup larva tersebut. Demikian juga pada rimpang $Z$. zerumbet menyebabkan kematian larva Ae. aegypti, sebagai larvisida yang berpotensi pengendali nyamuk.

\section{DAFTAR PUSTAKA}

1. Mulyatno KC, Yamanaka A, Ngadino, and Konish E. Resistance of Aedes aegypti (L.) Larvae to Temephos in Surabaya, Indonesia. The Southeast Asian Journal of Tropical Medicine and Public Health. 2012; 43(1): 29-33.

2. Prasetyowati H, Hendri J, dan Wahono T. Status Resistensi Aedes aegypti (Linn.) terhadap Organofosfat di Tiga Kotamadya DKI Jakarta. BALABA: Jurnal Litbang Pengendalian Penyakit Bersumber Binatang Banjarnegara. 2016; 12 (1): 23-30.

3. Grisales N, Poupardin R, Gomez S, Fonseca-Gonzalez I, Ranson $\mathrm{H}$, and Lenhart A. Temephos Resistance in Aedes aegypti in Colombia Compromises Dengue Vector Control. PLoS Negleted Tropical Diseases. 2013; 7(9): e2438.

4. Diniz MMCSL, Henriques ADS, Leandro RS, Aguiar $\mathrm{DL}$, and Beserr EB. Resistance of Aedes Aegypti to Temephos and Adaptive Disadvantages. Revista de Saúde Pública. 2014; 48(5): 775-782.

5. Alsheikh AA, Mohammed WS, Noureldin EM, et al. Studies on Aedes Aegypti Resistance to Some Insecticides in the Jazan District Saudi Arabia. Journal of the Egyptian Society of Parasitology. 2016; 46 (1): 209-216.

6. Kementrian Kesehatan Republik Indonesia. Pedoman Penggunaan Insektsida (Pestisida) dalam Pengendalian Vektor. Jakarta: Kementrian Kesehatan Republik Indonesia; 2012; p. 3-21.

7. Rattan RS. Mechanism of Action of Insecticidal Secondary Metabolites of Plant Origin. Crop Protection. 2010; 29: 913-920.

8. Chang CJ, Tzeng T, Liou S, Chang YS, and Liu I. Absence of Genotoxic and Mutagenic Effects of Zingiber zerumbet (L) Smith (Zingiberaceae) Extract. Evidence Bases Complementary Alternative Medicine 2012; 2012: 1-7.

9. Chien TY, Chen LG, Lee CJ, Lee FY, and Wang CC. Antiinflamatory Constituens of Zingiber zerumbet. Food Chemistry. 2008;110(3): 584-589.

10. Hashemi SR, Zulkifli I, Bejo $\mathrm{MH}$, Farida A, and Somchit MN. Acute Toxicity Study and Phytochemical Screening of Selected Herbal
Dapat disimpulkan bahwa ekstrak terpurifikasi larut PE rimpang $Z$. zerumbet mengandung golongan terpenoid dan mempunyai aktifitas larvisida terhadap larva instar IIIIV Ae. aegypti. Selain itu ekstrak terpurifikasi larut PE rimpang $Z$. zerumbet mengakibatkan adanya kerusakan morfologi larva berupa rusaknya cephal, thorak dan abdomen serta hilangnya rambut-rambut yang terdapat pada sisi abdomen. Dengan demikian masih perlu dilakukan penelitian lanjutan mengenai efek larvisida ekstrak terpurifikasi larut PE rimpang Z. zerumbet terutama mengenai senyawa aktif yang berperan dalam aktifitas sebagai larvisida. Diharapkan isolasi dan identifikasi senyawa aktif tersebut pada penelitian selanjutnya menjadi langkah awal dalam penemuan dan pengembangan larvisida sebagai alternatif bahan larvisida baru.

Aqueous Extract in Broiler Chicken. International Journal of Pharmacology. 2008; 4(5): 352-360.

11. BückerA, Falcao-Bücker NC, Nunez CV, Pinheiro CCS, and Tadei WP. Evaluation of Larvicidal Activity and Brine Shrimp Toxicity of Rhizome Extracts of Zingiber zerumbet (L) Smith. Revista da Sociedade Brasileira de Medicina Tropical. 2013; 46(3): 377-380.

12. Nur LA, Djamiatun K, dan Kartasurya MI. Pengaruh Ekstrak Daun Kersen (Muntingia calabura L) terhadap Kolesterol Darah, Soluble ICAM-1 dan Pembentukan Sel Busa pada Tikus dengan Diet Tinggi Lemak dan Kolesterol. Jurnal Kedokteran Brawijaya. 2017; 29(3): 202-208.

13. World Health Organization. Guidelines for Laboratory and Field Testing of Mosqiuto Larvicides. (Online) 2005. http://whqlibdoc.who.int/hq/2005/ WHO CDSWHO PESGCDPP 2005.13.pdf. [diakses tanggal 10 September2011]

14. Jang DS, Han AR, Park G, Jhon GL, and Seo EK. Flavonoid and Aromatic Compounds from the Rhizomes of Zingiber zerumbet. Archives of Pharmacal Research. 2004; 27(4): 386-389.

15. Dai DN, Thang TD, Chau LTM, and Ogunwande IA. Chemical Constituents of the Root Essential Oils of Zingiber rubens Roxb., and Zingiber zerumbet (L.) Smith. American Journal of Plant Sciences; 2013; 4(1): 7-10.

16. Singh $\mathrm{G}$ and Prakash S. Study of Liquid Chromatography and Mass Spectrometry of Memnoniella echinata Metabolites against Vector of Dengue and Chikungunya. Austin Chromatography. 2014; 1(3): 1-6.

17. Aisyah S, Sulistyowati E, dan Sari YDA. Potensi Ekstrak Biji Bengkuang (Pachyrrhizus Erosus Urb) sebagai Larvisida Aedes aegypti Larva Instar III. Kaunia. 2013: 9(1)1:1-11.

18. Ahbirami $R$, Zuharah WF, Thiagaletchumi $M$, Subramaniam S, and Sundarasekar J. Larvicidal Efficacy of Different Plant Parts of Railway Creeper, Ipomoea cairica Extract Against Dengue Vector Mosquitoes, Aedes albopictus (Diptera: Culicidae) and Aedes aegypti (Diptera: Culicidae). Journal of Insect Science. 2014; 14(180): 1-6.

19. Vieira JRC, Leite RMP, Lima IR, Navarro DAF, Bianco 
EM, and Leite SP. Oviposition and Embryotoxicity of Indigofera suffruticosa on Early Development of Aedes aegypti (Diptera: Culicidae). Evidence Based Complementary and Alternative Medicine. 2012; 2012: 1-5.
20. Sharma A, Kumar S, and Tripathi P. Impact of Achyranthes Aspera Leaf and Stem Extracts on the Survival, Morphology and Behaviour of an Indian Strain on Dengue Vector, Aedes aegypti L (Diptera: Culicidae). Journal of Mosquito Research. 2015; 5(7): 1-7. 